\title{
O URBANISMO PAULISTA DA PRIMEIRA METADE DO SÉCULO XX: UTOPIAS E REALIDADES ${ }^{1}$
}

Rodrigo Alberto Toledo ${ }^{2}$

\section{Resumo}

O presente artigo pretende demonstrar o constructo do pensamento e as ações concretas do urbanista Anhaia Mello, um dos pioneiros teóricos do urbanismo brasileiro. A recuperação de suas teses e dissertações possibilitou revelar uma ampla rede de relações e debates travados entre os principais urbanistas que se dedicaram, nas primeiras décadas do século XX, à transposição e à (re) significação de um conjunto de propostas urbanas que dialogavam com a problemática urbana das cidades industriais. Nosso procedimento de pesquisa contou com a sistematização de fontes documentais, decretos, leis, atos municipais e artigos escritos por urbanistas brasileiros que tematizaram a problemática urbana. A realidade paulistana das primeiras décadas do século XX foi sulcada por várias propostas de urbanização conduzidas, dentre outros, por Luiz Ignácio Romeiro de Anhaia Mello e Francisco Prestes Maia.

Palavras-chaves: urbanismo, planejamento urbano, políticas públicas, Anhaia Mello, Prestes Maia, São Paulo.

\section{EL URBANISMO PAULISTA DE LA PRIMERA MITAD DEL SIGLO XX: UTOPÍAS Y REALIDADES}

\section{Resumen}

El presente artículo pretende demostrar el constructo del pensamiento y las acciones concretas del urbanista Anhaia Mello, uno de los pioneros teóricos del urbanismo brasileño. La recuperación de sus tesis y disertaciones posibilitó revelar una amplia red de relaciones y debates trabados entre los principales urbanistas que se dedicaron, en las primeras décadas del siglo XX, a la transposición ya la (re) significación de un conjunto de propuestas urbanas que dialogaban con la problemática urbana de las ciudades industriales. Nuestro procedimiento de investigación contó con la sistematización de fuentes documentales, decretos, leyes, actos municipales y artículos escritos por urbanistas brasileños que tematizaron la problemática urbana. La realidad paulistana, de las primeras décadas del siglo XX fue surcaba por varias propuestas de urbanización conducidas, entre otros, por Luiz Ignacio Romeiro de Anhaia Mello y Francisco Prestes Ma.

\footnotetext{
${ }^{1}$ Artigo elaborado a partir dos resultados da pesquisa de pós-doutorado "Do projeto ao plano: uma análise do Centro de Pesquisa e Estudos Urbanísticos (CEPEU-FAU-USP) como instituto indutor do planejamento no estado de São Paulo", financiada pela Agência Governamental CAPES-PNPD. O presente texto é uma versão revisada do Capítulo 2, O urbanismo de Anhaia Mello: utopias e realidades, publicado no livro "Do projeto ao plano: a corrente urbanística paulista”, Editora RiMa, no ano de 2017.

${ }^{2}$ Doutor em Ciências Sociais pelo Programa de Pós-graduação em Ciências Sociais da Universidade Estadual Júlio de Mesquita Filho - Campus Araraquara (UNESP-FCLAr). E-mail: ro-toledo@ hotmail.com.br.
} 
Palabras clave: urbanismo, planificación urbana, políticas públicas, Anhaia Mello, Prestes Maia, São Paulo.

\title{
URBANISM IN SÃO PAULO STATE DURING THE FIRST HALF OF XX CENTURY: UTOPIAS AND REALITIES
}

\begin{abstract}
This work aims to present the construction of the thought and the concrete actions of urbanist Luiz Ignácio Romeiro de Anhaia Mello, one of the theoretical pioneers of Brazilian urbanism. The recovery of his theses and dissertations enabled to disclose a wide net of relations and debates carried out among the main urbanists that dedicated themselves, in the first decades of 20th century, to the transposition and (re)signification of a set of urban proposes that urban problems in industrial cities. Our procedure of research counted with documentary sources, decrees, laws, municipal acts, and paper written by Brazilian urbanists that approached the urban. The reality in São Paulo city during the first decades of 20th century was furrowed by several proposed of urbanization headed, among others, by Anhaia Mello and Francisco Prestes Maia.
\end{abstract}

Keywords: urbanism, urban planning, public policies, Anhaia Mello, Prestes Maia , São Paulo.

\section{INTRODUÇÃO}

Este artigo tem por objetivo apresentar alguns debates produzidos por urbanistas nas primeiras décadas do século XX, que marcaram o formato de crescimento da malha urbana da cidade de São Paulo. O debate sobre os rumos que a metrópole deveria tomar foi entrecortado pela institucionalização do ensino da formação do arquiteto-urbanista - mais tarde arquitetoplanejador -, conduzido, por sua vez, por profissionais-empresários como Antonio Francisco de Paula Souza, Francisco de Paula Ramos de Azevedo e Luiz de Anhaia Mello, pai de Luiz Ignácio Romeiro de Anhaia Mello, aqui denominado como Anhaia Mello.

Na primeira seção desse artigo, $O$ urbanista e a construção de uma proposta de cidade, apresentaremos as inquietações de Anhaia Mello e que, no limite, fornecerão as respostas ao urbanismo amalgamado por ele com o fito de colocar rédeas ao desenvolvimento urbano da cidade de São Paulo. O urbanista recorrerá a uma série de expedientes para implementar a sua proposta de cidade composta, fundamentalmente, pela aplicação de instrumentos urbanos que pudessem retrair o crescimento e descongestionar a metrópole.

A análise da documentação escrita, matéria-prima fundamental no presente trabalho, permitiu a identificação da consolidação de um urbanismo conectado, por seu turno, à prática 
urbanística americana, às correntes européias orientadas, sobremaneira, pelo inglês Ebenezer Howard com seu modelo de cidade jardim, por Tony Garnier, com a proposta de cidade industrial e, por fim, a Walter Gropius, com a proposta de um urbanismo progressista no provimento de habitações sociais, apresentado na segunda seção Um Conjunto de Propostas Urbanas: Ebenezer Howard, Tonny Garnier e Walter Gropius.

Na terceira seção, Anhaia Mello e Prestes Maia: as contradições das propostas para São Paulo, apresentaremos resumidamente as principais formulações dos condutores do debate sobre o modelo de expansão da metrópole paulistana. Antagonicamente, defendiam formatos que dialogavam com o zoneamento e limitação do crescimento urbano e, no outro extremo, com a implementação de obras de reurbanização que pudessem ajustar o desenvolvimento urbano aos ciclos de crescimento econômico da cidade.

\section{O URBANISTA E A CONSTRUÇÃO DE UMA PROPOSTA DE CIDADE}

\footnotetext{
A religião do Anhaia Mello era o urbanismo; escrevia sobre urbanismo, falava sobre urbanismo, tinha uma noção completa e perfeita do urbanismo... (Ficher, 2005, p. 143, apud Pimentel, 1986, p. 20)
}

Anhaia Mello foi um dos pioneiros teóricos do urbanismo brasileiro. A recuperação e suas dissertações, que abrangeram da Cidade Jardim de Ebenezer Howard à Escola de Chicago, possibilitaram revelar sua imbricada rede de relações e medidas seguidas por ele para a cidade de São Paulo.

Nesse sentido, um dos dados que esta pesquisa consolida em suas análises foi que o pioneirismo de Anhaia Mello não ficou restrito à cidade de São Paulo, mas irradiou-se para um conjunto de municípios paulistas. E, nesses municípios, contribuiu efetivamente para a cristalização de importantes instrumentos de política urbana, o que, no limite, também revelará o seu percurso reflexivo na elaboração de mecanismos para a transposição de um conjunto de propostas - gerados no âmbito do Centro de Pesquisa e Estudos Urbanísticos, CEPEU, por ele criado - que dialogam com um movimento mundial em que as soluções para os problemas urbanos estavam sendo revistas.

Portanto, durante a realização dos procedimentos de pesquisa, sentimos a necessidade de desnudar o percurso reflexivo feito por Anhaia Mello e que fez com que ele acumulasse conhecimento para interpretar, indicar, propor e intervir - num primeiro momento - na realidade problemática da metrópole industrial São Paulo. E, da mesma forma, com se pretendesse precaver outros municípios dos "males" urbanos enfrentados por ela, elaborou 
propostas urbanas que serviriam de "modelos" para o planejamento das cidades. Anhaia Mello elabora um pensamento urbanístico, que, como o movimento de um pêndulo, ora concebeu utopias de cidades, ora concebeu propostas concretas - junto de um complexo processo de ressignificação dos conceitos urbanísticos europeus e norte-americanos - que foram incorporadas por muitos municípios paulistas, como revelam os dados desta pesquisa.

Este estudo se propõe a apresentar as inquietações de Anhaia Mello - que são as mesmas que acometiam os urbanistas da primeira metade do século $\mathrm{XX}$ - e que forneceram suas respostas ao urbanismo amalgamado por ele, que pretendia colocar rédeas ao desenvolvimento urbano desprovido de regulamentação nas grandes metrópoles brasileiras. $\mathrm{O}$ urbanismo, proposto por Anhaia Mello, pretendia não somente influenciar no desenvolvimento de metrópole, mas de pequenos e médios municípios. Sua proposta não residia apenas na aplicação de instrumentos urbanos que pudessem conter, retrair o crescimento das cidades e descongestionar a metrópole, mas em propor um novo modelo de desenvolvimento racional, em que a riqueza gerada, no eixo composto pelas metrópoles Rio de Janeiro e São Paulo, pudesse ser redistribuída por meio do planejamento regional para desconcentrar a indústria que - já naquele momento - exauria os recursos naturais e a infraestrutura dessas cidades.

No entanto, para direcionarmos precisamente as intenções de Anhaia Mello, temos que, primeiramente, situá-lo nas correntes urbanísticas com suas respectivas respostas aos problemas urbanos. Nesse particular iremos, conceitualmente, apresentar as condições que se colocaram, no final do século XIX e início do XX, sobre os problemas do planejamento urbano. Pois, são esses problemas e a busca por suas respostas que nos levarão até as fronteiras do pensamento desse urbanista.

Torna-se fundamental, todavia, descrevermos o papel de Anhaia Mello em uma rede de profissionais que atuavam na consolidação da formação profissional do arquiteto e do urbanista. Trilharemos nosso percurso de análise, a partir da atuação de seu pai, Luiz de Anhaia Mello, na criação da estrutura da disciplina de Engenheiro-arquiteto, na Escola Politécnica de São Paulo. Com formação em engenharia civil, na cidade do Rio de Janeiro, no ano de 1875, atuou primeiramente na Cia. Mogiana de Estado de Ferro. Com consistente formação acadêmica, pois estudou instalações industriais na Europa e nos Estados Unidos, assumiu, ao retornar ao Brasil, a direção da Anhaia Fabril, que havia sido fundada por seus 
familiares, no ano de 1869, em Itu-SP, e que contava com uma unidade produtiva na cidade de São Paulo.

Além de diretor e empresário do ramo têxtil, foi um dos organizadores da Escola Politécnica, no ano de 1893, sendo seu vice-diretor e catedrático da disciplina Mecânica Racional para o curso de Engenheiro-arquiteto. As atividades da Escola Politécnica iniciaramse, efetivamente, no ano de 1894, com a publicação de um edital no Diário Oficial do Estado de São Paulo (DOSP, 1894, p.9070, apud FICHER, 2005, p. 25) que anunciava a abertura do processo seletivo à matrícula na Escola. Os primeiros cursos oferecidos foram os de Engenheiro Civil, Industrial e Agrícola. A Politécnica também oferecia um curso técnico, Artes Mecânicas, para aqueles que não possuíam o estudo ginasial exigido como pré-requisito para os exames preparatórios.

Anhaia Mello, influenciado por seu pai, iniciou as suas atividades de formação profissional no ano de 1909 e, no ano de 1913, concluía o curso de Engenheiro-arquiteto, diplomando-se pela Politécnica (FICHER, 2005).

Profissionalmente, dada à proximidade entre seu pai e Francisco de Paula Ramos de Azevedo $^{3}$, iniciou as suas atividades na empresa F. P. Ramos de Azevedo \& Cia. Anos mais tarde, entrou para a Cia. Iniciadora Predial, no ramo de financiamento e construção civil, fundada, em 1908, por Ramos de Azevedo e demais sócios.

A empresa Iniciadora Predial será a principal atividade profissional particular de Anhaia Mello, permanecendo como seu diretor até a sua dissolução em 1964. A Cerâmica Vila Prudente, outra empresa de Ramos de Azevedo, também foi dirigida por Anhaia Mello. No entanto, sua dedicação principal foi à docência, não apenas na Politécnica, mas em outras instituições, devido a sua constante produção teórica e militância política. Seu vínculo político, entretanto, deslocou-o para exercer funções fora da academia, na administração e no planejamento da cidade de São Paulo, sendo inclusive, seu prefeito. Concorreu com Alexandre Albuquerque, Bruno Simões Magno e Francisco Tito de Souza Reis à vaga de professor substituto da $4^{\mathrm{a}}$ Seção de Artes da Politécnica, ficando com o segundo lugar. Contudo, somente em 1918, assumirá como professor substituto dessa vaga, sendo nomeado, em outubro de 1919, e efetivado três anos depois, em 1922. (MELLO, sd ${ }^{\mathrm{a}}$, Escola Politécnica, 1918, p.10 apud FICHER, 2005, p. 144).

\footnotetext{
${ }^{3}$ Ramos de Azevedo, nasceu no ano de 1851 e entre 1875 e 1878, estudou na École Speciale Du Genie Civil ET Arts et Manufactures da Universidade de Grand, Bélgica. Depois de formado, estabeleceu-se como importante empresário em 1887, na cidade de São Paulo. Sócio de Antonio Francisco de Paula Souza e Joaquim Monteiro de Carvalho e Silva na Cia. Paraná Industrial, que explorava madeira, no ramo da construção civil.
} 
A partir de 1926, foi também efetivado como catedrático da cadeira "Estética. Composição Geral e Urbanismo I e II”, o que lhe introduzirá ao ensino daquilo que se tornaria a sua principal especialidade, o urbanismo. A produção intelectual de Anhaia Mello sempre se manteve ativa e, em 1926, publicou dois artigos: "Introdução ao Estudo da Estética" (MELLO, 1926a ) e "Estudo de Estética Sociológica" (crítica e produção da obra de arte)" $\left(\right.$ MELLO, $1926^{\mathrm{b}}$ ). Segundo Ficher (2005), no primeiro artigo, o autor elabora uma crítica ao racionalismo presente na formação do engenheiro ao afirmar que a instrução do engenheiro era toda dirigida à elaboração conceitual de uma proposta de cidade que se descolava das necessidades dos cidadãos.

No entanto, mesmo que elaborasse críticas à formação racional do engenheiro, não pensava que o progresso técnico fosse incompatível com a beleza. $\mathrm{O}$ seu texto revela um profissional marcado pelo ecletismo, chegando a afirmar que a arte, incorporada à arquitetura e ao urbanismo, não era algo moral nem imoral, mas amoral.

No segundo artigo escrito, revela uma preocupação com a função social da arte e conclui que a inspiração artística é autônoma. Sobre a prática como urbanista, por meio de seu vínculo político-partidário com o Partido Democrata, PD, já vinha atuando como vereador e apresentara à Câmara Municipal o Projeto, nº 1666, de 26 de março de 1913, que, por sua vez, negava as disposições da Lei, $\mathrm{n}^{0} 1193$, de 9 de março de 1909, e que tinha como objeto a exigência de custeio, por parte dos empreendedores das despesas com o calçamento entre guias em toda extensão das ruas a serem abertas. O debate travado pelo então vereador Anhaia Mello objetivava pressionar os empreendedores no aumento da participação nas principais despesas que concorriam, imediatamente, para a valorização do terreno a ser comercializado. O calçamento das ruas, para ele, era um fator decisivo na valorização dos lotes, fruto de novos parcelamentos do solo, pelo qual a cidade passava nessas primeiras décadas do século XX.

Em 1927, publicou outro artigo, intitulado "Problemas de urbanismo: mais uma contribuição para o calçamento" (MELLO, 1927, pp. 343-365), em que colocava às claras que a abertura de ruas deveria ser custeada pelos empreendedores, assim como já ocorria em outros países, como a França. Analisava, em 1927, que a despeito de existir a Lei ${ }^{0} 2611$, de 20 de junho de 1923, que criava restrições à abertura de vias de comunicação em qualquer perímetro do município sem o licenciamento da prefeitura, porém essa normativa não foi seguida pelos empreendedores. 
No artigo, "Um grande urbanista francês: Donat-Alfred Agache", de 1928, demonstrava um significativo domínio da bibliografia internacional, sendo um dos difusores de diversas concepções em solo brasileiro, como demonstraremos mais à frente. Sua combativa atuação, no final da década de 1920, projetou o seu nome no meio profissional da cidade de São Paulo, rendendo-lhe seis convites para ministrar conferências sobre os princípios gerais do urbanismo, conforme sistematizamos no quadro 1.

Quadro 1- Primeiro ciclo de conferências ministradas por Anhaia Mello (1928-1929)
\begin{tabular}{|c|l|l|}
\hline ANO & \multicolumn{1}{|c|}{ TEMA } & \multicolumn{1}{c|}{ CENTRO DO DEBATE } \\
\hline 1928 & $\begin{array}{l}\text { O problema psicológico: bases de uma } \\
\text { campanha prática e eficiente em prol de } \\
\text { São Paulo maior e melhor. }\end{array}$ & $\begin{array}{l}\text { Apresenta suas reflexões em defesa de uma } \\
\text { expansão urbana regulada da cidade de São } \\
\text { Paulo. }\end{array}$ \\
\hline 1928 & $\begin{array}{l}\text { O problema psicológico: as Associações } \\
\text { Americanas de Urbanismo. }\end{array}$ & $\begin{array}{l}\text { Propunha uma divisão de Urbanismo no } \\
\text { Instituto de Engenharia e defendia a } \\
\text { atribuição profissional dos arquitetos. }\end{array}$ \\
\hline 1928 & A cidade, problema de governo. & $\begin{array}{l}\text { Abordou o problema do crescimento } \\
\text { desordenado das cidades, como fator } \\
\text { relacionado à baixa capacidade de } \\
\text { governabilidade das prefeituras municipais. }\end{array}$ \\
\hline 1929 & O governo das cidades. & $\begin{array}{l}\text { Abordou a ocupação ilícita do solo na } \\
\text { cidade de São Paulo e apresentou as } \\
\text { soluções implementadas nas cidades } \\
\text { estadunidenses. }\end{array}$ \\
\hline 1929 & $\begin{array}{l}\text { Urbanismo: } \\
\text { expropriação. }\end{array}$ & $\begin{array}{l}\text { Abordou o urbanismo como sendo a área } \\
\text { fundamental para regular o parcelamento } \\
\text { do solo urbano e sua utilização lícita. }\end{array}$ \\
\hline 1929 & Urbanismo: o problema financeiro. & $\begin{array}{l}\text { Descreve os exemplos de cidades } \\
\text { americanas e suas aplicabilidades em São } \\
\text { Paulo, capital. }\end{array}$ \\
\hline
\end{tabular}

Fonte: Ficher, 2005.

As seis conferências, descritas no Quadro 1, foram reunidas em um livro publicado, em 1929, "Problemas de urbanismo: bases para resolução do problema técnico" (MELLO, $1929^{a}$ ) . O centro do debate de Anhaia Mello gravita em torno de dois grandes temas: a necessidade de se regulamentar a carreira profissional de Arquiteto, desvinculada da de Engenheiro, como ocorria na grade curricular da Escola Politécnica, e a apresentação de "modelos" de cidades (estadunidenses) que possuíam arcabouço normativo necessário para impor rédeas ao desenvolvimento urbano, uma necessidade premente da metrópole São Paulo, segundo o urbanista.

Um segundo ciclo de conferências (1929 a 1930), proferidas por Anhaia Mello e que teve uma repercussão significativa no meio profissional, os temas debatidos tinham uma ampla gama de conceitos e informações que foram introduzidas como referenciais para os 
profissionais vinculados ao Instituto de Engenharia da cidade de São Paulo. O conferencista discutiu questões que iam desde o suprimento de energia elétrica - em um momento de mudança no formato de concessão de propriedade de diversos empresários brasileiros para firmas americanas - até a necessidade de regulamentação, pelo poder público municipal, de uma série de outros serviços de utilidade pública, como apresentamos abaixo, no quadro 2 :

Quadro 2-Segundo ciclo de conferências ministradas por Anhaia Mello (1929-1930)
\begin{tabular}{|l|l|l|}
\hline ANO & \multicolumn{1}{|c|}{ TEMA } & \multicolumn{1}{|c|}{ CENTRO DO DEBATE } \\
\hline 1929 & $\begin{array}{l}\text { Urbanismo: o recreio ativo e organizado } \\
\text { das cidades modernas. }\end{array}$ & $\begin{array}{l}\text { Dialogou com concepções urbanísticas que } \\
\text { elaboraram modelos de cidades industriais e } \\
\text { alternativas para o controle da ocupação do } \\
\text { solo. }\end{array}$ \\
\hline 1929 & A verdadeira finalidade do urbanismo. & $\begin{array}{l}\text { Conferência proferida em comemoração à } \\
\text { primeira reunião da Divisão de Urbanismo } \\
\text { do Instituto de Engenharia. }\end{array}$ \\
\hline 1930 & $\begin{array}{l}\text { Natureza, classificação, características } \\
\text { econômicas dos serviços de utilidade } \\
\text { pública. }\end{array}$ & $\begin{array}{l}\text { Estabelece diálogo próximo a urbanistas } \\
\text { progressistas e culturalistas sobre, } \\
\text { fundamentalmente, as funções das zonas } \\
\text { urbanas. }\end{array}$ \\
\hline 1930 & $\begin{array}{l}\text { Regulamentação dos serviços de utilidade } \\
\text { pública. }\end{array}$ & $\begin{array}{l}\text { Retoma conceitos urbanísticos, como cidade- } \\
\text { jardim e unidade de vizinhança, para pensar } \\
\text { os problemas da cidade industrial São Paulo. }\end{array}$ \\
\hline
\end{tabular}

Fonte: Ficher, 2005.

Uma parcela desse material utilizado pelas conferências serviu para o autor publicar o livro: "Problemas de urbanismo: o recreio ativo e organizado nas cidades modernas" $\left(\right.$ MELLO, $1929^{\mathrm{b}}$ ). Depreendemos desse processo que a produção intelectual (publicação de artigos, livros e traduções) e a realização de conferências (como as sistematizadas nos quadros anteriormente apresentados) projetaram o nome de Anhaia Mello como uma importante referência no urbanismo paulista e brasileiro. Pensamos que, para além dessa constatação, sua atuação se deu como um mecanismo de ressignificação e implantação das correntes urbanísticas-progressistas e culturalistas no Brasil. À essa etapa do desenvolvimento intelectual-reflexivo de Anhaia Mello, somam-se as descritas anteriormente, tais como, sua atuação junto à Escola Politécnica (como professor interino de Ramos de Azevedo) e, depois, como seu vice-diretor, no ano de 1928, e, sobremaneira, como político. Primeiramente, como vereador e, depois, em 1930, como prefeito da cidade de São Paulo, indicado pelo governo provisório do interventor, João Alberto Lins de Barros (25 de nov. 1930 - 25 de jul. de 1931), pelo mesmo Partido Democrata ao qual estava filiado. (FICHER, 2005). Evidentemente, essa escalada profissional e política não se deveu a apenas méritos pessoais, a despeito de 
provavelmente possuí-los. Há uma trajetória social, que se define a partir de condicionantes históricos, políticos e econômicos pelo qual passava o Estado de São Paulo, do final do século XIX até 1930, que projetava o sentido ascendente da classe (ou grupos de classes) ao qual pertencia Anhaia Mello. A descrição de sua formação acadêmica e o modo de inserção no mercado de trabalho revelam-nos a rede social ao qual ele estava conectado, desde as relações consolidadas pelo seu pai, Luiz de Anhaia Mello (amigo de Antonio Francisco de Paula Souza, um dos organizadores da Escola Politécnica, e de Ramos de Azevedo, empresário de sucesso no ramo da construção civil e catedrático da Politécnica, por exemplo).

Em outros termos, a posição dele na estrutura de classe da elite paulistana, portanto, estava ligada, sincronicamente, ao futuro da posição, que é o sentido da sua trajetória social, dada pelas relações consolidadas mesmo antes de seu nascimento (BOURDIEU, 2013).

A despeito de não ter ficado muito tempo como prefeito, tendo sido seu nome cogitado para substituir João Alberto e este seria, na verdade, substituído por Laudo Ferreira Camargo (25 de jul. de 1931-13 de nov. de 1931), atuou no sentido de tentar aplicar parte de suas concepções urbanísticas à realidade paulistana. A tese nuclear do pensamento de Anhaia Mello era que São Paulo não deveria expandir-se indefinidamente e, sobretudo, sob bases ilícitas - tese defendida claramente em suas conferências desde a década de 1920. Assim, modificará e/ou instituirá, como prefeito, um conjunto de atos, dentre os quais, o de número 21, de 17 de dezembro de 1923, que lhe isentava de responsabilidades ao proprietário de terreno urbano nos custos da pavimentação feita pela Prefeitura Municipal, ao qual não concordava. Introduziu modificações no Código Arthur Saboya (Lei número 3427, de 19 de novembro de 1929), como, por exemplo, a determinação de recuos mínimos entre edificações e de coeficientes máximos de aproveitamento da área a ser construída nos terrenos. Este último direcionamento objetivava controlar o adensamento de determinadas regiões da cidade de São Paulo.

O Ato número 127, de 20 de março de 1931, institui o regulamento diferencial de espacialização, também denominado zoning (zoneamento), em algumas regiões da cidade, tema que, por sua vez, havia sido abordado na conferência: "Urbanismo: regulamentação e expropriação”. Claramente, Anhaia Mello, pretendia, com seus atos, criar restrições ao, até então observável, crescimento desorganizado e ilícito da cidade. A passagem do urbanista pela prefeitura foi relativamente curta, mas intensa em Atos instituídos, que objetivavam organizar os "descaminhos" da metrópole durante o seu processo de desenvolvimento 
industrial. Em 1931, foi substituído das funções de prefeito por Laudo Ferreira Camargo (25 de jul. de 1931 - 13 de nov. de 1931), retomando suas atividades na Politécnica. (FOLHA DE SÃO PAULO, 1931, p.1 apud FICHER, 2005, p. 147).

Entretanto, nesse mesmo ano, quando da posse do general interventor Manoel Rabelo (13 de nov. de 1931 - 7 de mar. De 1932), como governador do estado, Anhaia Melo retomaria o cargo de prefeito, ocupando-o por apenas 20 dias, de 14 de novembro a 4 de dezembro de 1931. Apesar do curto tempo de atuação, decretou sete legislações, sendo a mais expressiva a instituída pelo ato número 265, de 26 de novembro de 1931, objetivando a inibição da construção de postos de combustíveis em áreas estritamente residenciais.

\section{UM CONJUNTO DE PROPOSTAS URBANAS: EBENEZER HOWARD, TONNY GARNIER E WALTER GROPIUS}

Em 1932, retoma as aulas de sua cátedra, sem perder o vínculo político e teórico com os conceitos urbanísticos. Influenciado, nesse momento, pela prática urbanística americana, que, por sua vez, estabelece relações de proximidade e distanciamento com correntes urbanísticas europeias orientadas, destacadamente, num primeiro momento, pelo inglês Ebenezer Howard e seu modelo de cidade-jardim, e por Tony Garnier, com a proposta de cidade industrial. Francês de Lyon, Garnier, era discípulo de Paul Blondel ${ }^{4}$ e dedicou parte de sua vida à elaboração de um projeto, tido como o revolucionário em 1901, de uma cidade modelo. Entretanto, somente em 1917, escreve a obra, "Uma cidade industrial", que exercerá considerável influência em um conjunto de urbanistas progressistas. Ao se partir do princípio de que a Carta de Atenas 5 seja um importante marco do urbanismo progressista, "Uma cidade industrial" poderia ser considerada o primeiro manifesto dessa corrente, anterior à consolidação da Carta. A proposta contida em "Uma cidade industrial" pode ser dimensionada como um marco, fundamentalmente, por instituir um conjunto de princípios diretores à análise e à separação das funções urbanas, ao destaque dado aos espaços verdes (que cumpririam a função de elementos isoladores) e a utilização sistemática de elementos

\footnotetext{
${ }^{4}$ Paul Blondel (1847-1897) foi um arquiteto francês formado pela Escola de Belas Artes de Paris. A partir de 1880, tornou-se professor titular da Cadeira de Arquitetura para a Escola Nacional de Artes e Decoração da França. Era um fervoroso simpatizante das ideias socialistas. (CHOAY, 2013; LAMAS, 2014).

${ }^{5}$ Documento produzido a bordo do navio Patris (navegando entre Marselha e Atenas) durante o IV CIAM no ano de 1933. Constitui-se em uma síntese das proposituras dos congressos anteriores em um texto dogmático e polêmico que orientava, estabelecendo critérios, a organização das cidades. Tornou-se público só em 1941, por iniciativa de Le Corbusier que escreve sua versão final, orientando o texto de acordo com suas convicções.
} 
novos aos projetos arquitetônicos das construções, como o concreto armado. (CHOAY, 2013).

Os desenhos de Garnier são mais audaciosos que suas construções; há uma referência constante à antiguidade, principalmente, em seus projetos residenciais, que utilizam o átrio ${ }^{6}$ como um de seus componentes. A obra de Garnier, focada por Choay (2013), assume posição de destaque, pelo fato de ter sido por meio dela que o autor pôde exercer um papel de protagonista no processo criativo da arquitetura moderna. Para este, as novas cidades deveriam ser fundadas sob a égide da economia industrial com características rigidamente pré-estabelecidas, no momento de sua concepção, tais como:

1. Porte médio, do ponto de vista populacional, até 35 mil habitantes;

2. Estar próxima a centros produtores de matérias-primas, ou seja, a um mercado de trabalho suscetível de ser utilizado;

3. Estar inserida em uma rede de circulação que facilitasse o transporte de insumos (destinados às indústrias) e ao escoamento de mercadorias.

O aspecto setorizado de sua concepção de cidade é perceptível, quando Garnier trata dos elementos considerados nucleares por ele, tais como: fábrica, cidade e estabelecimentos hospitalares. O pensador reforça a opção pela setorização, pelo zoneamento por fruição, em uma cidade como sendo o fio condutor para o estabelecimento da ordem ao caos (referimonos ao acelerado processo de urbanização das cidades industriais desprovido de ações de planejamento).

Essa opção, no entanto, guindou o autor a refletir e criar regulamentos sobre essas disposições setorizadas das funções em uma cidade: regulamentos de inspeção de limpeza e regulamentos sanitários, dentre outros. Da mesma forma, Garnier passou a categorizar outros espaços urbanos de acordo com o uso do solo ou fruição para que esse determinado serviço passasse a ser ofertado ao cidadão na malha urbana.

Ao tratar do tema habitação, Garnier elabora orientações que irão desde a disposição de portas e janelas até os tipos de materiais que deveriam ser utilizados. Esse conjunto de regras impostas para a habitação serão incorporadas ao que, no Brasil, denominamos Código de Obras, presente, via de regra, em todos os municípios. Esses códigos, assim como as orientações de Garnier, instituem a regulamentação do parcelamento do solo urbano, no que diz respeito à metragem mínima do lote (geralmente $150 \mathrm{~m}^{2}$ ) e à taxa de ocupação do lote ou

\footnotetext{
${ }^{6} \mathrm{O}$ termo átrio surge na arquitetura grega e romana para designar o pátio central da casa. Na atualidade, também designa uma sala espaçosa de um hotel ou edifício público, que dá acesso a outra área de mais importância.
} 
área construída (geralmente, inferior à metade da superfície total, sendo que o restante do lote não poderá ser impermeabilizado). Além desses aspectos normativos, que confirmariam, na concepção de Garnier, uma racionalidade no desenvolvimento urbano, preocupa-o a própria disposição dos lotes nos bairros, de maneira que deixassem uma passagem livre (desimpedida de barreiras físicas como cercas e muros) e que permitissem atravessar a cidade, em qualquer sentido, sem a necessidade de transitar pelas ruas. A baixa taxa de ocupação do lote, somada à exigência de não impermeabilização do terreno, conferiria ao solo da cidade, como um todo, o aspecto de um grande parque, sem nenhum muro divisório que limitasse as unidades habitacionais.

A cidade industrial e a racionalidade de seu desenvolvimento será abordada por Walter Gropius, essencialmente um catedrático da reconhecida escola de Baubaws ${ }^{7}$ e que, posteriormente, desempenhou suas atividades na Faculdade de Arquitetura de Harvard, pois Baubaws havia sido fechada por ordem do governo nazista, em 1933, marcando efetivamente duas gerações de urbanistas.. Gropius pertence a um grupo maior ${ }^{8}$, composto por Mies Van de Rohe, Le Corbusier, Oud e Mendelson, que fundou a arquitetura racionalista ${ }^{9}$, um tipo de arquitetura que recorria constantemente ao aço, vidros e formas geométricas despojadas nos projetos de prédios.

No tocante à concepção urbanística, os termos principais difundidos por Gropius giravam em torno de conceitos de padronização, de pré-fabricação e da criação de um espaço que dialogasse com o movimento progressista que a arquitetura vivia naquelas décadas iniciais do século XX. Esses pressupostos foram aplicados em duas cidades operárias planejadas por este, Dammerstock de Karlsruhes (1927-1928) e o Siemensstadt de Berlim

\footnotetext{
${ }^{7}$ A Staattiches-Baubaws foi uma escola de design, artes plásticas e arquitetura de vanguarda na Alemanha. Bauhaws foi uma das maiores e mais importantes expressões do que é chamado modernismo no design e na arquitetura. A escola foi fundada em 1919 por Walter Gropius. (BENEVOLO, 2009).

${ }^{8}$ Erich Mendelson (1887-1953) foi um reconhecido arquiteto expressionista. Sua principal obra foi a Einsteinturm.Facobus Fohannes; Pieter Oud (1890-1963) foi um arquiteto neerlandês, seguidor da corrente arquitetônica do neoplasticismo e principal representante do movimento moderno em seu país; Ludwing Mies Van de Rohe (1886-1969) foi um arquiteto alemão naturalizado americano, considerado um dos principais nomes da arquitetura racionalista do século XX, pautada pela utilização de uma geometria clara e pela sofisticação.

${ }^{9}$ A arquitetura nacionalista é uma corrente surgida na Europa, após a Primeira Guerra Mundial. Conjuga, em sua
proposta, todos os propósitos racionalizadores e funcionalistas da arquitetura da Revolução Industrial, cujo
objetivo era encontrar um caminho entre a simples imitação do antigo e a um excessivo tecnicismo
padronizador. (BENEVOLO, 2009).
}

Sociedade e Território - Natal. Vol. 29, N. 2, p. 06-29, Jul./Dez. de 2017 
$(1928)^{10}$. Essas cidades/bairros serão o modelo do urbanismo progressista e servirão de inspiração para outras intervenções, que gerariam estudos de alojamentos em série, no tipo de habitação denominada de casa-pré-fabricada, principalmente nos EUA.

Ao analisar a cidade como um todo, Gropius parte de observações sobre a rua considerada como uma unidade superior - para, depois, focar as células que compõem um segundo grupo-tipo de caráter econômico ou residencial. A concepção de cidade-standart está relacionada a intervenções processadas em meio urbano e que promovam uma hegemonia, que, para este, é a "marca própria de uma cultura urbana superior" (GROPIUS apud CHOAY, 2013, p. 177).

A proximidade de Gropius não se dava apenas na dimensão das ideias, mas também por meio da participação em eventos realizados no Brasil, como na $1^{\text {a }}$ Bienal de São Paulo, em 1951, e que serviram de ponte na criação de uma identificação, por exemplo, do IAB/SP com as artes plásticas de vanguarda e com a proposta progressista (moderna) de arquitetura Figura 1.

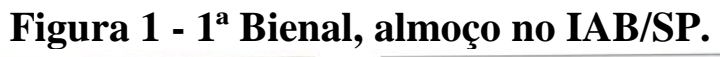
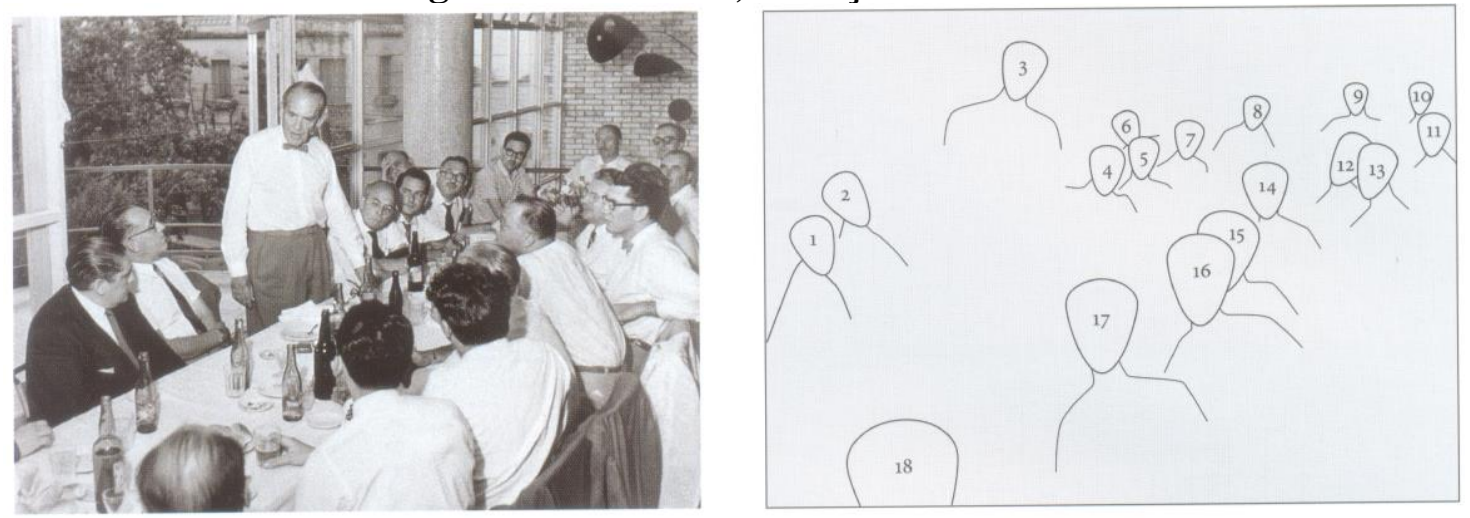

Fonte: Ficher, 2005, p. 251.

Legenda: À direita a identificação: 1. Jorge Machado Moreira, 2. Rino Levi, 3. Walter Gropius, 4. Arquiteto da Prefeitura, 5. Gilberto Junqueira Caldas, 6. João Cacciola, 7. Ariosto Mila, 8. Não identificado, 9. Eduardo Kneese de Mello, 10. Oswaldo Corêa Gonçalves, 11. Abelardo de Souza, 12. Carlos Lodi, 12. Não identificado, 14. Ícaro de Castro Mello, 15 a 18. Não identificáveis. Arquivo Oswaldo Corrêa Gonçalves.

A concepção de Gropius sobre a cidade passa pela regulamentação dos tipos-padrões de edifícios do ponto de vista dos materiais utilizados na sua construção e, evidentemente, na orientação normativa do gabarito desses edifícios. Ações que, do seu ponto de vista, confeririam latitude e organização ao desenvolvimento urbano. Essa é, também, a constante

\footnotetext{
${ }^{10}$ Bairro residencial operário que levou esse nome, dado a sua proximidade com a fábrica Siemens e que, portanto, atenderia principalmente seus trabalhadores.
} 
referência a que fará Anhaia Mello com o fito de estimular, no urbanismo paulistano, novas bases normativas e econômicas. Os estudos elaborados, este último em o "Código de ocupação lícita do solo", do ano de 1956, apontam para a necessidade de se criar parâmetros normativos que pudessem frear o desenvolvimento acelerado e "desorientado" da conurbe paulistana, que se expandia a golpes de empreendimentos urbanísticos privados que geravam novos bairros. (TOLEDO, 2013).

Anhaia Mello, conectado visceralmente a essas concepções, pois forneciam instrumentos importantes para a releitura do espaço paulistano, publicará inúmeros trabalhos que tinham como pano de fundo a criação de planos reguladores, para cidades em franco processo de expansão da malha urbana, impulsionado pelo desenvolvimento industrial. Para tanto, necessitava criar e implementar arcabouço legal-normativo para a desapropriação de terrenos urbanos, corresponsabilização dos empreendedores imobiliários com a infraestrutura mínima dos novos bairros e, sobretudo, implantar aparato fiscalizador suficiente para intervir nos rumos da expansão urbana da cidade de São Paulo, ditados, até então, pelo capital imobiliário especulativo, conforme apresentamos no quadro 3.

Quadro 3 - Produção teórica de Anhaia Mello no período de 1932 - 1937.

\begin{tabular}{|l|l|l|}
\hline ANO & \multicolumn{1}{|c|}{ TEMA } & \multicolumn{1}{|c|}{ CENTRO DO DEBATE } \\
\hline 1932 & A economia da terra urbana. & $\begin{array}{l}\text { Apresenta uma teoria da utilização de áreas } \\
\text { urbanas para combate aos vazios e à } \\
\text { especulação imobiliárias. }\end{array}$ \\
\hline 1933 & $\begin{array}{l}\text { Urbanismo e suas normas para } \\
\text { organização de planos. }\end{array}$ & $\begin{array}{l}\text { Conceitua sobre o que é urbanismo, com } \\
\text { base nos textos de autores estrangeiros, } \\
\text { como Patrick Geddes e Cyrus Keehr. } \\
\text { Aponta para a importância do } \\
\text { planejamento regional e descreve as etapas } \\
\text { para a elaboração de um plano. }\end{array}$ \\
\hline 1933 & Os arautos da tecnocracia. & $\begin{array}{l}\text { Faz referência à história da tecnocracia, } \\
\text { movimento que surgiu com o objetivo de } \\
\text { solucionar a crise mundial no período } \\
\text { entre-guerras. Segundo os autores } \\
\text { analisados, a crise era tecnológica e não } \\
\text { política, por isso que a solução deveria ser } \\
\text { de ordem técnica. São apresentados quadro } \\
\text { "chefes da tecnocracia", assim } \\
\text { classificados por Anhaia Mello: Walter } \\
\text { Rautenstrauch, Basset Jones e Howard } \\
\text { Scott. }\end{array}$ \\
\hline 1933 & $\begin{array}{l}\text { A cidade celular, quadras, superquadras } \\
\text { e células residenciais. }\end{array}$ & $\begin{array}{l}\text { Elabora defesa do tipo de planejamento } \\
\text { urbano em que as malhas, entre as vias } \\
\text { principais, possuíssem todas as atividades } \\
\text { necessárias à vida do consumidor. Remete } \\
\text { à ideia de cidade funcional. }\end{array}$ \\
\hline
\end{tabular}

Sociedade e Território - Natal. Vol. 29, N. 2, p. 06-29, Jul./Dez. de 2017 
Continuação - Quadro 3

\begin{tabular}{|c|c|c|}
\hline ANO & TEMA & CENTRO DO DEBATE \\
\hline 1933 & Traffic Planning e Traffic Control. & $\begin{array}{l}\text { Analisa os problemas causados pelo } \\
\text { tráfego urbano e da necessidade de seu } \\
\text { controle por meio da Engenharia de } \\
\text { Tráfego. São utilizados exemplos os } \\
\text { Estados Unidos, Inglaterra, França e } \\
\text { Alemanha. }\end{array}$ \\
\hline 1934 & $\begin{array}{l}\text { Novos subsídios para a regulamentação } \\
\text { dos serviços de utilidade pública. }\end{array}$ & $\begin{array}{l}\text { Artigo produto de uma série de } \\
\text { conferências realizadas no Club de } \\
\text { Engenharia do Rio de Janeiro, em } \\
\text { dezembro de } 1933 \text {. Trata da relação entre } \\
\text { propriedade privada e interesse público, do } \\
\text { sistema de concessão para o fornecimento } \\
\text { de energia elétrica e das características do } \\
\text { serviço público }\end{array}$ \\
\hline 1936 & $\begin{array}{l}\text { Um programa de habitação para os } \\
\text { Estados Unidos. }\end{array}$ & $\begin{array}{l}\text { Análise de estudos realizados pela National } \\
\text { Association of Housing Officials, tendo } \\
\text { como base catorze cidades americanas } \\
\text { (Nova York, Cleveland, Washington, } \\
\text { Boston, Detroit, Chicago, Milwaukee, } \\
\text { Saint Loius, New Orleans, Atlanta, } \\
\text { Knouxville, Cincinatti, Pittsburg e } \\
\text { Philadelphia) comparando-as às cidades } \\
\text { brasileiras. }\end{array}$ \\
\hline 1937 & $\begin{array}{l}\text { O rational planning board e o Plano } \\
\text { Nacional dos Estados Unidos. }\end{array}$ & $\begin{array}{l}\text { História do Plano Nacional implantado nos } \\
\text { Estados Unidos por Franklin Roosevelt. }\end{array}$ \\
\hline 1937 & $\begin{array}{l}\text { Pierre Charles l'Enfant e o Plano da } \\
\text { Cidade Federal. }\end{array}$ & $\begin{array}{l}\text { Revela dados biográficos de l'Enfan - } \\
\text { arquiteto que elaborou o Plano de } \\
\text { Washington. }\end{array}$ \\
\hline
\end{tabular}

Fonte: Ficher, 2005 e banco de dados do Urbanismobr.org ${ }^{11}$.

Em 1941, Anhaia Mello participará de importantes obras na capital, como a direção das intervenções na Catedral de São Paulo, e especificamente ficará responsável pela cúpula e pelas duas torres. No mesmo ano, assume como diretor da Faculdade de Filosofia Ciências e Letras da Universidade de São Paulo e afasta-se como catedrático da Escola Politécnica para assumir a direção da Secretaria de Viação e Obras Públicas de São Paulo, durante o governo de Fernando de Souza Costa (4 de jun. de 1941 - 27 de out. de 1945). A sua atuação como Secretário pautou-se, principalmente, na implantação de um novo plano rodoviário para a cidade de São Paulo. No cargo, participou de diversas atividades cerimoniais-comemorativas,

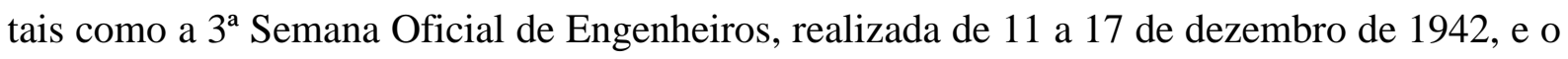
Vigésimo quinto aniversário da fundação do Curso de Engenheiros-arquiteto da Escola de Engenharia da Universidade Presbiteriana Mackenzie. No entanto, em virtude da violenta

\footnotetext{
${ }^{11}$ Dados da rede urbanismobr, disponíveis no site www.urbanismobr.org, consultado em 25 de set. de 2015.
} 
repressão policial a manifestantes contra a ditadura varguista, no Largo São Francisco, exonerou-se do cargo e retomou as atividades acadêmicas e intelectuais diante das questões urbanas de São Paulo. (FICHER, 2005).

\section{ANHAIA MELLO E PRESTES MAIA: AS CONTRADIÇÕES DAS PROPOSTAS PARA SÃO PAULO}

Contudo, desde meados da década de 1930, o conjunto de propostas elaboradas por Anhaia Mello para o equacionamento dos problemas da cidade de São Paulo, reverberaram na proposta de cidade do então, empreendedor e prefeito, Francisco Prestes Maia ( $1^{\circ}$ de maio de 1938 - 10 de nov. de 1945) ${ }^{12}$. Anhaia Mello iniciou um debate com Prestes Maia pelos jornais, quando da abertura das avenidas Ipiranga e 9 de Julho. Quanto à primeira, sua crítica se ateve ao fato de que iria se prolongar apenas até à Igreja da Consolação e, no caso da segunda, que o seu prolongamento provocaria o estrangulamento do tráfego no túnel sob a Avenida Paulista. (FICHER, 2005).

Até meados da década de 1960, o confronto entre os dois urbanistas (Anhaia Mello e Prestes Maia) seria constante e ganharia os jornais na exposição, defesa e críticas elaboradas por ambos. Nas palavras de Carlos Alberto Gomes Cardim Filho ${ }^{13}$ :

\footnotetext{
Acho que uma das fraquezas nosso urbanismo [refere-se ao urbanismo paulistado] vendo o fato de Anhaia Mello e Prestes Maia, dois homens de valor, não rezarem pela mesma cartilha e serem contraditório em suas próprias posições. [...] Se você quiser um plano teórico, muito bem estudado, em legislação americana: Anhaia. Já um plano mais realista e experimentado: o Maia. (FICHER, 2005, p.148).
}

Em que pese os dois urbanistas divergirem em muitos aspectos correlatos ao modelo de desenvolvimento urbano da cidade de São Paulo, em 25 de janeiro de 1935, participaram da criação da sociedade Amigos da Cidade de São Paulo. Uma entidade de direito privado, elaborada para pressionar o Poder Público municipal, na criação de ações voltadas para pressionar o poder público municipal na criação de ações voltadas para o planejamento e melhoramentos urbanos. Segundo Anhaia Mello, a Sociedade cumpriria o papel de mobilizar

\footnotetext{
${ }^{12}$ Prestes Maia era um importante urbanista e político paulistano contemporâneo de Anhaia Mello. No entanto, por divergirem quanto à proposta de modelo de cidade, o primeiro era progressista e o segundo culturalista, entraram em atrito por diversas vezes. $\mathrm{O}$ auge das intervenções urbanas elaboradas por Prestes Maia dar-se-á no período de seu primeiro mandato como prefeito da capital paulista (1938-1945). Ordenou um conjunto de reformas que acabaram com os bondes para abrir avenidas (implementação de seu Plano de Avenidas), túneis, subterrâneos e elevados para autos.

${ }^{13}$ Ficher, Sylvia. Depoimento gravado prestado a Sylvia Ficher. São Paulo 12 de set. de 1985, 23 de jan. de 1986 e 14 mar. De 1986. 3 vol. (FICHER, 2005).
} 
a energia cívica suficiente para exigir melhoramentos, planos regulares e o progresso da sociedade. As associações, ao lado de grupos técnicos, segundo o urbanista, criariam um "clima", uma "temperatura moral" para o urbanismo. Para ele, portanto, o urbanismo não deveria ser imposto por lei ou manipulação, mas seria um problema educacional. Nitidamente, há uma alteração de seu modus operandi, fruto, provavelmente, da larga experiência que acumulara ao desempenhar o papel de prefeito da capital paulista, mesmo que por curtos períodos de tempo. Durante seus dois breves mandatos, instituiu normas, leis e decretos que objetivavam impor, à "canetada", restrições à dinâmica especulativa de que deu o tom da expansão da malha urbana de São Paulo. Segundo ele, as associações, como a “Sociedade Amigos da Cidade de São Paulo", seriam responsáveis por criar o ambiente necessário para a urbanização racional, pois a metrópole paulistana, que assistiu a um acelerado crescimento populacional, em um curto espaço de tempo, em 1890, possuía 65.000 habitantes e chegou a 1.100 .000 em $1935^{14}$-, acumulava dados comprometedores da qualidade de vida urbana.

No entanto, as propostas construídas no âmbito da Sociedade Amigos da Cidade de São Paulo, somente seriam executadas após a saída de Prestes Maia da cadeira de prefeito de São Paulo e, sobretudo, a partir da transformação da Secretaria de Obras e Serviços Municipais em Secretaria de Obras pelo Decreto-lei n ${ }^{\circ} 431$, de 8 de julho de 1947, ou seja, uma década depois da criação da Comissão do Plano da Cidade, preconizada pelos integrantes da Associação.

A primeira Comissão formada foi nomeada pela Portaria Municipal, $\mathrm{n}^{\mathrm{o}} 708$, de 8 de agosto de 1948, final de mandato do então prefeito Paulo Lauro (19 de ago. de 1947 - 25 de ago. de 1948). No entanto, a Comissão não desenvolveu suas atividades e, apenas em 1953, durante a gestão do prefeito Jânio da Silva Quadros (8 de abr. de 1953 - 6 de jul. de 1954), assumiu novo formato e iniciou suas atividades a partir da entrada em vigor da Lei $\mathrm{n}^{\mathrm{o}} 4494$, de 14 de jun. de 1954. O Artigo 44 da Lei 4494, além de criar a comissão, estabeleceu um espaço composto por diversos representantes da sociedade civil, órgãos da Administração Pública Municipal e Universidades, em que deveriam:

\footnotetext{
${ }^{14}$ Dados populacionais apresentados no artigo publicado no Boletim do Instituto de Engenharia, $\mathrm{n}^{\mathrm{o}}$ 115, vol. 11 , 21 de jun. de 1935, pp. 263-269.
} 
[...] apreciar, quando solicitado pelo Executivo ou Legislativo municipal, os projetos relativos ao plano da cidade e os problemas relacionados com a execução dos serviços de utilidade pública podendo também apresentar sugestões para a realização e solução de problemas gerais de urbanismo. (FICHER, 2005, p. 149).

A Comissão Orientadora será o palco de intensos debates sobre como deveriam ser o Plano Diretor do município. Os principais condutores do debate sobre a forma de expansão da cidade serão Anhaia Mello e Prestes Maia. De maneira contraditória, ambos defendiam formatos distintos de condução pelo poder público municipal, do modelo de desenvolvimento urbano. O primeiro apostava no zoneamento e na limitação do crescimento urbano da cidade, mesmo que para isso tivesse que recorrer à desindustrialização da cidade. Prestes Maia, por sua vez, defendia que as obras de reurbanização implementadas pelo Poder Público, tais como a abertura ou o alargamento de vias, deveriam estar ajustadas a um novo Código de Obras que pudesse lidar com a malha urbana a partir do referencial do zoneamento por adensamento. Em outros termos, Maia pensava ser possível reorganizar as forças que impulsionavam o desenvolvimento urbano a partir da disseminação de áreas, dotadas com infraestrutura, para a criação de empreendimentos imobiliários que pudessem adensar a população em determinadas regiões da cidade.

Parece-nos que esse contínuo embate de ideias conduziram Anhaia Mello para, reflexivamente, aglutinar as correntes urbanísticas as quais vinha mantendo efetivos contatos na elaboração do estudo "Elementos Básicos para o Planejamento Regional de São Paulo" conjunto de ideias que ficarão conhecidas como o "Esquema Anhaia". A proposta foi submetida à Comissão Orientadora do Plano, que contou como parecerista o conselheiro Prestes Maia. O conteúdo da proposta revela o cerne do pensamento de Anhaia Mello para resolver a problemática urbana de São Paulo. Ele destacava diferentes abordagens diante dos problemas urbanos, sistematizando-as, basicamente, em duas: a prática e a científica. A primeira, de acordo com suas observações, não logrou êxito e se inviabilizou por meio de ações pontuais que promoveram "remendos neste ou" [naquele] " setor de nossa cidade". (FICHER, 2005, p. 149). Nesse trecho, Anhaia Mello direciona, rasgadamente, uma crítica ao tipo de urbanismo intervencionista e de grandes obras e planos viários de Pestes Maia.

A abordagem científica, por sua vez, possibilitaria a aplicação das orientações do urbanismo moderno para, principalmente, desobstruir o trânsito e o embelezamento de praças e vias arteriais de circulação. Entretanto, a questão central da polêmica entre os dois urbanistas, era a proposta contida no "Esquema Anhaia", que dava relevo à necessidade da 
proibição da instalação de novas indústrias em São Paulo e instituía restrições ao crescimento do município.

Prestes Maia, de espírito conservador, era refratário a propostas drásticas para resolver os problemas e, no limite, acusa Anhaia Mello de pretender "ananicar" a cidade industrial, que já despontava como uma das maiores metrópoles da América Latina.

A proposta de limitação do crescimento da cidade, nuclear no pensamento urbanístico de Anhaia Mello, somente seria realizada a partir do controle da especulação imobiliária e pelo zoneamento. A preocupação central era com a cidade, com a problemática urbana oriunda, em suas análises, a partir da prevalência dos interesses particulares da Cia. Light, que interferia efetivamente no parcelamento do solo urbano paulistano em acordos preestabelecidos com empreendedores imobiliários. Ele se esforçava na criação de um tipo de urbanismo independente, de caráter local e descolonizador, do ponto de vista da tomada de decisões necessárias para se produzir soluções urbanas adequadas. Anhaia Mello não fez um tipo de arquitetura moderna, mas conhecia os movimentos modernistas renovadores sem que, no entanto, impusesse aos seus alunos ou auxiliares, quando tinham que projetar algo, a elaboração de um projeto de estilo modernista.

Para Anhaia Mello, o fundamento da arquitetura era tornar belos e eficientes os edifícios projetados no século XX. Em segundo, defendia uma arquitetura criativa, livre de preceitos históricos e que pudesse, ao mesmo tempo, se servir de todos os novos materiais que a ciência e a indústria modernas produziam. E, por fim, utilizava como referência um terceiro fundamento do pensamento contemporâneo, a ideia da inovação estética, lógica e, ao mesmo tempo, simplicidade das linhas arquitetônicas. Portanto, ele não era contra o modernismo, pois possuía uma formação filosófica e artística, do ponto de vista estético e funcional de suas propostas.

Como prova de sua postura, podemos citar o fato de ele ter sido o principal articulador, junto ao Governo do Estado, da criação da Faculdade de Arquitetura e Urbanismo (FAU), da Universidade de São Paulo (USP), instituída pelo Decreto, $\mathrm{n}^{\circ}$ 104, de 21 de junho de 1948. E será como professor da FAU, que Anhaia Mello consolidará um conjunto de ideais ligados, por um lado, ao conhecimento técnico da construção e, pelo outro, ao racionalismo arquitetônico. Sua principal preocupação era o urbanismo, orientado pelo debate estético dentro da concepção moderna de arquitetura. Segundo Ficher (2005), em 1951, chegou a 
convidar Oscar Niemeyer para lecionar na FAU. Entretanto, dada à filiação política (comunista) de Niemeyer, a reitoria vetou o contrato.

\section{CONSIDERAÇÕES FINAIS}

O quadro da evolução urbana da cidade de São Paulo, na primeira metade do século XX, foi orientado pela especulação imobiliária com o lançamento de diversos loteamentos separados do núcleo urbano, o que gerou inúmeros vazios urbanos preenchidos paulatinamente pelas urbanizadoras.

A Companhia City certamente foi a mais destacada urbanizadora que atuou em São Paulo nesse momento da história do desenvolvimento da cidade analisado em nosso artigo. A Cia. City assumiu importância, pois implementou loteamentos para classes abastadas com um padrão urbanístico novo no Brasil, as cidades-jardins.

Paralelamente ao processo de desenvolvimento urbano da cidade de São Paulo, identificamos um processo de deterioração da qualidade de vida de classes sociais menos abastadas o que levou, por sua vez, ao desenvolvimento de duas ações capitaneadas por urbanistas paulistanos.

Primeiramente, a ação de uma rede de profissionais para a institucionalização da formação do arquiteto e do urbanista. A Escola Politécnica de São Paulo, a Faculdade de Arquitetura e Urbanismo do Mackenzie e, mais tarde, a Faculdade de Arquitetura e Urbanismo da Universidade de São Paulo, foram instituições que, articuladas às associações de classe como o Instituto dos Arquitetos do Brasil, IAB, criaram um mercado de trabalho de reserva para os egressos dessas instituições de ensino nos grandes centros urbanos em franco processo de expansão. Em específico a criação da FAUUSP representará um capítulo importante na trajetória do urbanista Anhaia Mello, pois com proposta curricular diferenciada

- elaborada com ampla participação de Anhaia Mello -, possibilitará a formação de Arquitetos-urbanistas, ao contrário que a sua homônoma Escola Politécnica vinha fazendo desde o final do século XIX, com a formação de Engenheiros-arquitetos. A formação de Arquitetos-urbanistas, na concepção de alguns estudiosos, garantiria a geração de um campo de pesquisa autônomo, com menor dependência das concepções teóricas fincadas nas ciências exatas de leitura do espaço urbano.

Em segundo, uma nova grade curricular - com a fundação da FAUUSP -, voltada para a formação de técnicos urbanistas que nutriria o mercado e o poder público das 
administrações municipais, com formação acadêmica conectada às leituras das cidades industriais européias e americanas elaboradas, por sua vez, por um pensamento urbanístico mundial em processo de cristalização nos Congressos Internacionais de Arquitetura Moderna, os CIAM's. Em outros termos, contribuiria para a criação de planos reguladores para cidades em franco processo de expansão da malha urbana. Para tanto, há a percepção de que era fundamental implementar arcabouço legal normativo que pudesse conter o ciclo especulativo que propulsava a expansão da malha urbana e, ao mesmo tempo, corresponsabilizar os empreendemores imobiliários com a infraestrutura mínima dos novos bairros.

No entanto, como podemos verificar nas análises produzidas nesse artigo, não havia na cidade de São Paulo um pensamento homogêneo a respeito do modelo de desenvolvimento urbano a ser implementado pelo poder público municipal. Identificamos duas vertentes que formularam duas propostas distintas de desenvolvimento da malha urbana. Anhaia Mello, vinculado claramente aos conceitos racionais de um urbanismo modernista, apostava no zoneamento e na limitação do crescimento urbano da cidade de São Paulo. Prestes Maia, por seu turno, defendia um tipo de reurbanização, implementada pelo poder público, que pudesse dar suporte ao desenvolvimento urbano conduzido por companhias incorporadoras que atuavam "livremente" em solo paulistano. Portanto, a abertura ou alargamento de vias, presentes em um novo Código de Obras Municipal, conectaria áreas dotadas de infraestrutura que pudessem acomodar a população em vazios urbanos produzidos pelo capital especulativo imobiliário que grassava no território da cidade de São Paulo.

\section{REFERÊNCIAS}

CHOAY, Françoise. (2013). O urbanismo: utopias e realidades. São Paulo: Perspectiva.

FELDMAN, Sarah. (2005). Planejamento e Zoneamento. São Paulo 1947-1972. São Paulo: Editora da Universidade de São Paulo/Fapesp.

FERNANDES, Florestan. (1987). Cap. 5 - A concretização da revolução burguesa. (IN) A revolução burguesa no Brasil: ensaio de interpretação sociológica. Rio de Janeiro: Guanabara.

FICHER, Sylvia. (2005). Os arquitetos da Poli: ensino e profissão em São Paulo. São Paulo: Edusp.

MELLO, Luiz I. de Anhaia. (1926a). Introdução ao estudo da estética. USP.

MELLO, Luiz I. de Anhaia. (1926b). Ensaio de estética sociológica (Crítica e produção da obra de arte). Revista Politécnica, São Paulo, n. 82, pp. 205-220, set. de. 
(1926c). Introdução ao estudo da estética. Revista Politécnica, São Paulo, n.81, pp. 127-139, jun. de 1926. calçamento. USP.

.(1927d). Problemas de urbanismo: mais uma contribuição para o . (1928a). A cidade. Conferência realizada no Instituto de Engenharia de São Paulo, s/d.

.(1928b). O governo das cidades. Conferência realizada no Instituto de Engenharia de São Paulo, s/d.

.(1928c). O Problema psicológico: as Associações Americanas de Urbanismo. Publicado com o título Urbanismo. Conferência realizada no Instituto de Engenharia em 08 de novembro de 1928.

.(1928d). O problema psicológico: bases de uma campanha prática e eficiente em prol de São Paulo maior e melhor. Conferência proferida no Rotary Club de São Paulo, s/d.

. (1928e). Um grande urbanista francês: Donat-Alfred Agache. USP.

- (1929a). Problemas de Urbanismo - Bases para a resolução do problema technico (sic.). Boletim do Instituto de Engenharia de São Paulo. São Paulo.

(1929b). Problemas de urbanismo: o recreio ativo e organizado nas cidades modernas. São Paulo, Boletim do Instituto de Engenharia.

.(1929c). Urbanismo: o problema financeiro. Conferência proferida no Instituto de Engenharia de São Paulo, s/d.

.(1929d). Urbanismo: regulamentação e expropriação. Conferência realizada no Instituto de Engenharia, s/d.

Instituto de Engenharia, s/d.

. (1930a). A verdadeira finalidade do urbanismo. Conferência realizada no

. (1930b). Natureza, classificação, características econômicas dos serviços de utilidade pública. Conferência realizada no Instituto de Engenharia.

1930c. Regulamentação dos serviços de utilidade pública. Conferência realizada no Instituto de Engenharia, s/d.

. (1930d). Urbanismo: o recheio ativo e organizado das cidades modernas. Conferência realizada no Instituto de Engenharia, s/d. de Engenharia.

(1932-1933). Economia da Terra Urbana. Conferência realizada no Instituto

(1933). Organização de Planos. Conferência realizada no Instituto de Engenharia.

(1934). Novos Subsídios para a Regulamentação dos Serviços de Utilidade Pública. Conferência realizada no Instituto de Engenharia.

. (1935). Sociedade Amigos da Cidade de São Paulo. Boletim do Instituto de ${\text { Engenharia, } \mathrm{n}^{\mathrm{0}}} 115$, vol. 11, 21 de jun. de 1935, pp. 263-269 
(1936). Um Programa de Habitação para os Estados Unidos, Conferência Realizada no Instituto de Entenharia.

.(1937a). A National Planning Board e o Plano Nacional dos Estados Unidos, Conferência Realizada no Instituto de Engenharia,1937.

. (1937b). Pierre Charles L'Enfant e o Plano da Cidade Federal, 1937.

. (1956). O Plano Regional de São Paulo - Uma Contribuição da Universidade para o estudo de Um Código de Ocupação Lícita do Solo. São Paulo: FAUUSP, mimeo.

. (1957). Elementos para o planejamento territorial dos municípios. São Paulo: Centro de Pesquisa e Estudos Urbanísticos, FAUUSP, 1957.

TOLEDO, Rodrigo Alberto. Do projeto ao plano: a corrente urbanística paulista. São Carlos, São Paulo: Editora RiMa, 2017.

\section{Documentos jurídicos}

\section{Legislação do Imperial e Federal}

BRASIL (Estado-Império). Decreto imperial $n^{0}$ 2.922, de 10 de maio de 1862. Criou o corpo de engenheiros civis no Ministério da Agricultura, Comércio e Obras Públicas.

BRASIL (Estado). Decreto $n^{\circ}$ 23.569, de 11 de dezembro de 1933. Criou o Conselho Federal de Engenharia e Agronomia.

BRASIL (Estado). Lei $\mathrm{n}^{\mathrm{o}}$ 12.378, de 31 de dezembro de 2010. Criou o Conselho de Arquitetura e Urbanismo (CAU).

\section{Legislação do Estado de São Paulo}

SÃO PAULO (Estado). Decreto ${ }^{\circ}$ 1.992, de 20 de dezembro de 1910. Regulamenta o ensino na Escola Politécnica de São Paulo.

SÃO PAULO (Estado). Decreto $\mathrm{n}^{0}$ 1.992, de 27 de janeiro de 1911. Estabelece novas orientações para o ensino na Escola Politécnica de São Paulo.

SÃO PAULO (Estado). Decreto $n^{\circ} 5.361$, de 18 de janeiro de 1932. Reorganiza o Conselho de Orientação Artística e extingue fim ao curso de Arquitetura da Academia de Belas Artes.

Legislação do Município de São Paulo

SÃO PAULO (Município). Lei n ${ }^{\circ} 2611$, de 20 de junho de 1923. Cria restrições à abertura de vias de comunicação em qualquer perímetro do município de São Paulo.

SÃO PAULO (Município). Lei n ${ }^{0}$ 3427, de 19 de novembro de 1929 [Código Arthur Saboya], determina recuos mínimos entre edificações, dentre outras normativas.

SÃO PAULO (Município). Ato $\mathrm{n}^{\circ} 127$, de 20 de março de 1931. Institui o regulamento diferencial de espacialização (zoneamento).

SÃO PAULO (Município). Decreto-Lei $n^{\mathbf{0}}$ 431, de 8 de julho de 1947. Transforma a Secretaria de Obras e Serviços Municipais em Secretaria de Obras.

SÃO PAULO (Município). Decreto n ${ }^{\circ}$ 104, de 21 de junho de 1948. Cria a Faculdade de Arquitetura e Urbanismo da Universidade de São Paulo - FAUUSP. 
SÃO PAULO (Município). Portaria Municipal $n^{\circ} 708$, de 8 de agosto de 1948. Institui a primeira Comissão do Plano da Cidade de São Paulo.

SÃO PAULO (Município). Lei n ${ }^{\circ} 4494$, de 14 de junho de 1954. Institui, pela segunda vez, a Comissão do Plano da Cidade de São Paulo.

Recebido em Junho de 2017

Aprovado em Outubro de 2017

Publicado em Dezembro de 2017 